\title{
Investigation of Management Innovation Process Based on Conflict-solving Method by TRIZ Theory
}

\author{
Min WANG ${ }^{1, a}$, Dong-Sheng ZHANG ${ }^{2, b, *}$, Li ZHANG ${ }^{3, c}$ \\ 1,2,3 School of Economics and Management, Hebei University of Technology, Tianjin 300130, China

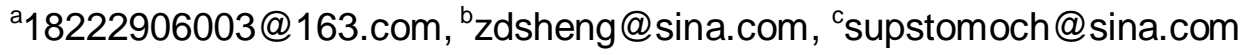 \\ ${ }^{*}$ Corresponding author
}

Keywords: Management innovation, Management conflicts, TRIZ, Enterprise environmental parameters.

\begin{abstract}
TRIZ theory has been widely applied to the technical innovation. However it still lacks of efficient conflict-solving tools in the field of management innovation. In the study, we overview the use of tool in TRIZ for solving the technical and management innovation problem, such as the 40 Inventive Principles and 39 Technical Parameters that have been commonly applied. Our overview found that the 40 Inventive Principles can be used for the conflict-solving of management innovation, while the 39 Technical Parameters should be revised before its application. The Enterprise Environmental Parameters are necessary to solve the Management Conflict Matrix. The ideality of the innovation should be measured in the process to get the optimal solution.
\end{abstract}

\section{Introduction}

At present, the nation has generally recognized the significant importance of innovation management, especially for the enterprise, where the innovation ability has become a core ability to meet with the competence. To promote the ability of innovation, methodology such as TRIZ can be applied. It has broad application prospects in the management field as reported by many domestic and abroad experts [1]. Mann (1999) argued that TRIZ can provide a powerful framework for the system definition and problem solution regarding the business, organization, management and so on [2]; for most of the TRIZ tools, the method should be directly or slightly modified to suit with several non-technical areas [2]. Zlotin and Zusman (2001) also believed that most of the basic TRIZ concepts, such as the conflict and system methods can be directly applied to problems in the non-technical field [3]. Following that, several TRIZ experts investigated TRIZ theory in many application cases in the field of management innovation. Fey and Rivin (1997) proposed a perspective of TRIZ methodology for management innovation [4]. Hipple (2004) used TRIZ to solve conflict in the practice of organization innovation [5]. Martin et.al (2004) applied principles of TRIZ for the strategic deciding in enterprises [6]. Vries et al (2008) applied it to eliminate the emotional conflicts among organizations and employees [7]. Those researchers found that the application of TRIZ in problem-solving must consider the actual situation of the management system. It is, however, less practiced and lack of experience in the management innovation process such as for the conflict-solving.

Therefore, this paper will introduce the basic TRIZ theory and the facing problems in the application process. Based on that, we intend to suggest the direction of further development of the theory for the management innovation.

\section{TRIZ Theory}

TRIZ means the 'theory of inventive problem solving' [8]. TRIZ research started from its creator Altshuller, who consider that the creative thinking about the nature itself and the technology has its own embedded rules [8]. The main purpose of the theory is to study the principle and law that followed by the mankind in the process of innovation to solve the technical problems. TRIZ not only puts forward the strategy of the problem solving method, but also provides a series of standardized 
tools to guide the process of innovation, such as Conflict Matrix, 40 Inventive Principles, standard solution, the interaction analysis and so on [1]. In addition, the TRIZ provides a useful measure to overcome the inertia of thinking. It was developed to solve problems, create new ideas and innovation in the processes of technology development [3]. The TRIZ yields a high advantage to solve the problems and promote the innovation than other measures as reported by Ilevbare, et al. (2013) [1]. This is because it can give more precise knowledge-based solution to the problem.

\section{TRIZ in Technology and Management Innovation}

The problem-solving process of TRIZ can be solved by the tool of contradiction. Contradiction is applied to account for the incompatibility of a system to acquire the desired outcomes. Several tools has been applied most commonly in the technological field for the concept of contradiction, such as the 40 Inventive Principles and the Contradiction Matrix (also named as Conflict Matrix) [9]. The 40 Inventive Principles gives the possible conceptual solutions to the technical contradictions of the system. The Conflict Matrix is a matrix of 39 Technical Parameters that are arranged on the vertical and horizontal axis to interact with one another. It is used to point out the inventive principles that can be applied to solve the technical contradictions.
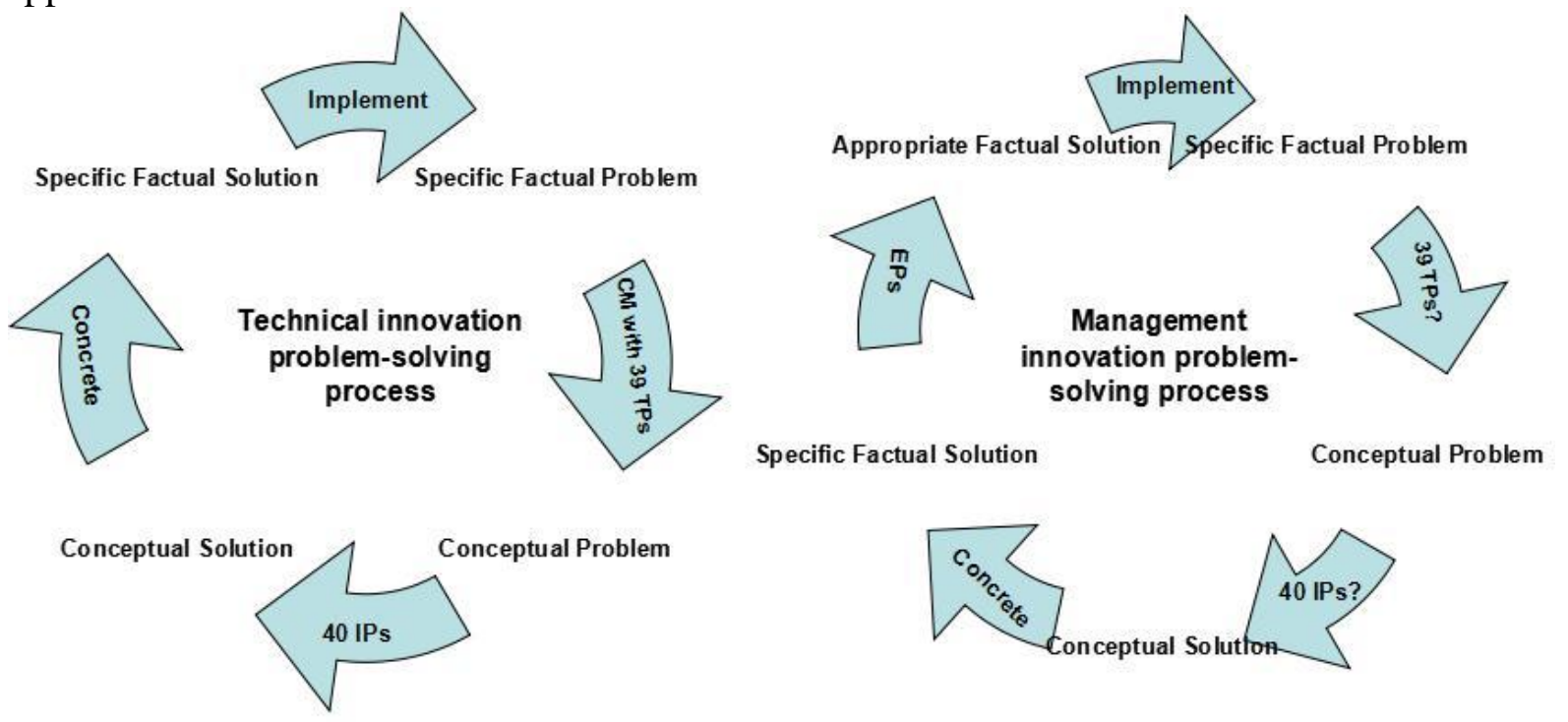

Figure 1 The general process for the problem-solving in technical and management field. IPs, TPs and EPs represent the Inventive, Technical and Environmental parameters, respectively.CM means the contradiction matrix of the TPs.

Figure 1 shows the process of solving technical and management invention problems by TRIZ. A specific factual problems was identified and defined at the beginning as a technical conflict regarding to the specific technology field. Later, one can turn the conflict into conceptual terms by using standard 39 Technical Parameters. The 39 Technical Parameters according to the problem can be filled into a Conflict Matrix. Once one or a few inventive principles were selected, several principles must be followed to produce a specific solution according to the specific problem. The role of the principle is to make the original innovation towards the direction of improvement. The principle must determine with carefully consideration according to the specific problems.

Previous practice has shown that more than one inventive principle should be considered for the Conflict Matrix [9]. 40 Inventive Principles were most commonly applied to solve the normal technical conflict. It has to be noted that these 40 principles can only be applied to obtain the feasible direction but not the exact solution, because several choice was ignored during the process that leading to a diverged direction of solution. It is recommended to include all inventive principles for the problem-solving. Once all principles did not meet the requirements, it was necessary to redefine the principles. 
In terms of the management innovation, the Enterprise Environmental Parameters must be considered in addition to the innovative and technical parameters [10]. As seen in Fig. 1, the enterprise environment parameters can be applied to screen the inappropriate solutions from the Conflict Matrix for the management innovation. The Enterprise Environmental Parameters must be correspondent to the practical situation of the enterprise, while technical innovation does not necessarily consider it.

In TRIZ process for the technical innovation, 39 Technical Parameters can be followed to turn the specific factual problem into a conceptual problem. While in management innovation, the parameters must be redefined according to the enterprises [11]. As well, the number of innovative principles must change accordingly.

In Fig. 1, the appropriate conceptual solution was different from the specific factual solution and specific conceptual solution. The latter was commonly applied in TRIZ to acquire usual solutions, which can be called as "ordinary solutions". There may be many conceptual solutions deriving from the Conflict Matrix. However, for a specific conflict, a portion of the general conceptual solution must be eliminated according to the existing knowledge and experience of managers.

In terms of the technical innovation, the specific factual solution of the product can be directly acquired from the conceptual solution. While the management innovation problems cannot. This is because even though a specific factual solution is suitable for some businesses enterprises, but may not be appropriate to other enterprises.For example, if one get a specific solution as "use divisional system", the solution is suitable for a large enterprises, but not appropriate for a small ones.

There is another type of Enterprise Environmental Parameters need to be taken into account.For example, if the "separation of powers" or "diversity" is a specific factual solution, but the "separation of powers" to what degree?"diversity" to what degree? All these question should be considered in the Enterprise Environmental Paramters.To deal with this, we use the degree of "appropriate solution" in the systematic chart as shown in Figure 1.

\section{Inventive Principles and 39 Management Parameters for Conflict-solving}

TRIZ experts thought the 40 Inventive Principles cannot be directly applied in expressing the conflicts [12, 13]. D. Mann (2004) [12] and O. Farias (2006) [13] further studied the 40 Inventive Principles for management innovations. Table 1 shows an application example about the invective principles. Mann introduced TRIZ to the field of management innovation firstly [12]. His idea was important for the next development of management innovation tools.He thought most of the TRIZ tools should be directly and slightly modified before applying to non-technical areas. For instance, 40 Inventive Principles can be applicable in the business field. Due to the fact that management field was diversified, multidimensional and complicated, it was necessary to develop the tools of inventive principles in TRIZ. Besides, to have sophisticated experience in business innovation would greatly benifit the use of the tool. Moreover, the conflict management should consider the win-win (win - win) case, rather than the zero-sum (win - lose) strategy.

In these processes, the Management Parameters should involve several parameters such as the features, dimensions, time, cost, risk and interface. Mann and Farias listed 31 Management Parameters that were important to the conflict-solving in mangement innovation as shown in Table 2. Mann's research focuses on the area of enterprise operation cohesion, while Farias focuses on the areas of supply chain management. One can see from Table 2 is that the common principles should include the reliability, efficiency, profitability, maintenance, inventory management, integrated level, quality, innovation, risk management, cost management, time management, support, service level, and so on. Other parameters such as information flow, interaction with other chains and on differs slightly between two researches. The basic framework of two reseraches was similar. One thing seen from Table 2 is that the Management Parameters should be revised according to the specific problem before the application in the management innovation. 
Table 140 Inventive Principles in management innovation

\begin{tabular}{|c|c|c|c|}
\hline 1 Segementation & $\begin{array}{l}11 \text { Beforehand } \\
\text { cushioning }\end{array}$ & 21 Hurry(Skipping) & $\begin{array}{l}31 \text { Hole } \\
\text { (Porous materials) }\end{array}$ \\
\hline 2 Taking out & $\begin{array}{l}\text { 12Remove tension } \\
\text { (Equipotentiality) }\end{array}$ & $\begin{array}{l}22 \text { "Blessing in } \\
\text { disguise" or } \\
\text { "Turn lemons into } \\
\text { lemonade" }\end{array}$ & 32 Color changes \\
\hline 3 Local quality & $\begin{array}{l}13 \text { The Other Way } \\
\text { Round }\end{array}$ & 23 Feedback & 33 Homogeneity \\
\hline 4 Asymmetry & $\begin{array}{l}14 \\
\text { Spheroidality-curvature }\end{array}$ & 24 Intermediary & $\begin{array}{l}34 \text { Recover } \\
\text { (Discarding and } \\
\text { recovering) }\end{array}$ \\
\hline 5 Merging & 15Dynamics & 25 Self-service & 35 Parameter changes \\
\hline 6 Universality & $\begin{array}{l}16 \text { Slightly } \\
\text { (partial or excessive } \\
\text { actions) }\end{array}$ & 26 Copying & 36 Phase transitions \\
\hline 7 “Nested Doll”" & 17 Another dimension & $\begin{array}{l}27 \text { Cheap short-living } \\
\text { objects }\end{array}$ & $\begin{array}{l}37 \text { Relative change } \\
\text { (Thermal expansion) }\end{array}$ \\
\hline $\begin{array}{l}8 \text { Counterweight } \\
\text { (Anti-weight) }\end{array}$ & 18 Mechanical vibration & $\begin{array}{l}28 \text { Another sense } \\
\text { (Mechanics } \\
\text { substitution) }\end{array}$ & $\begin{array}{l}38 \text { Enrich } \\
\text { (Strong oxidants) }\end{array}$ \\
\hline $\begin{array}{l}9 \text { Preliminary } \\
\text { anti-action }\end{array}$ & 19 Periodic action & $\begin{array}{l}29 \text { Fluid } \\
\text { (Pneumatics and } \\
\text { hydraulics) }\end{array}$ & $\begin{array}{l}39 \text { Calm } \\
\text { (Inert atmosphere) }\end{array}$ \\
\hline $\begin{array}{l}10 \text { Preliminary } \\
\text { action }\end{array}$ & $\begin{array}{l}20 \text { Continuity of useful } \\
\text { action }\end{array}$ & $\begin{array}{l}30 \text { Thin and flexible } \\
\text { (Flexible shells and thin } \\
\text { films) }\end{array}$ & $\begin{array}{l}40 \text { Composite } \\
\text { structures }\end{array}$ \\
\hline
\end{tabular}

The table was referred to the literature by Mann (2004) [12], in the bracket is the modification by Farias (2006)[13].

Table 231 Management Parameters in management innovation

\begin{tabular}{|c|c|c|}
\hline $\begin{array}{l}\text { 1 Quality management } \\
\text { (Spec/Capability/Means) }\end{array}$ & 12 Supply costs & $\begin{array}{l}23 \text { Information flow } \\
\text { (Communication flow) }\end{array}$ \\
\hline 2 Costs management & 13 Supply times & $\begin{array}{l}24 \text { System affected harmful } \\
\text { effects }\end{array}$ \\
\hline 3 Time management & 14 Supply risks & $\begin{array}{l}25 \text { Interaction with other chains } \\
\text { (System generated side effects) }\end{array}$ \\
\hline 4 Risks management & 15 Supply interfaces & 26 Management convenience \\
\hline 5 Interface management & 16 Reliability & 27 Adaptability/Versatility \\
\hline 6 Production management & 17 Supply costs & 28 System complexity \\
\hline 7 Production costs & 18 Support times & 29 Control complexity \\
\hline 8 Production times & 19 Support risks & 30 Competitiveness pressure \\
\hline 9 Production risk level & 20 Support interfaces & 31 Stability \\
\hline 10 Production interfaces & $\begin{array}{l}21 \text { Demand forecasting } \\
\text { (Customer revenue/Demand) }\end{array}$ & \\
\hline $\begin{array}{l}11 \text { Supply quality } \\
\text { (Customer } \\
\text { revenue/Demand) }\end{array}$ & 22 Information amount & \\
\hline
\end{tabular}




\section{Process Model to Solve the Management Problems}

In spite of Innovative Principles and Management Parameters, TRIZ also has complete process to solve the technical and management innovation conflict. The process model for technical innovation did not consider the Enterprise Environmental Parameters [8]. Several process models based on management innovation still did not consider the parameters [14, 15, and 16]. In order to consider the parameter in the TRIZ, this paper proposed a new process model of management innovation based on the above discussion as shown in Figure 2.

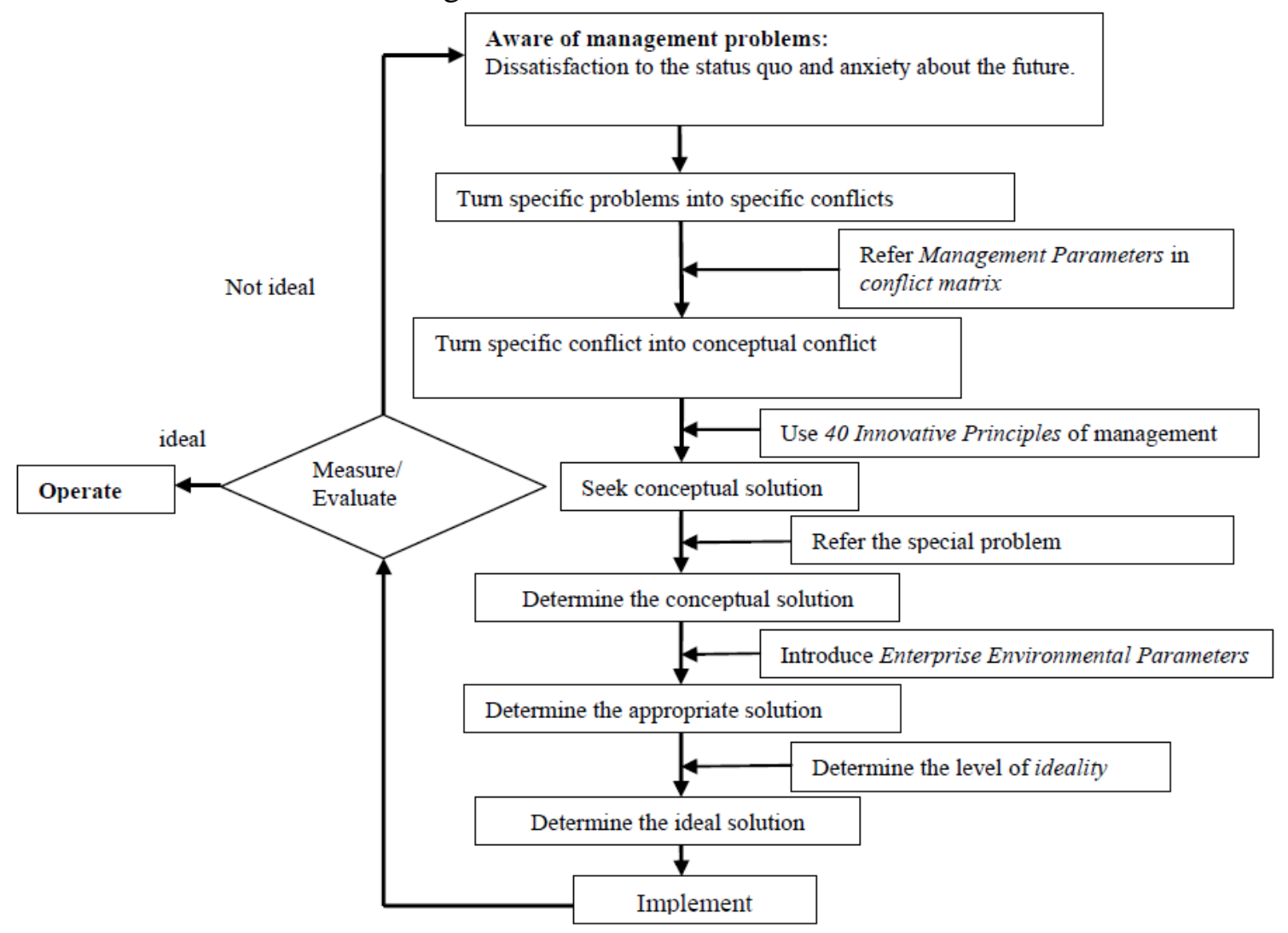

Figure 2 the process model of management innovation based on TRIZ

The process model in Figure 2 was consisted by eight steps: (1) Be aware of management problems. In the start of innovation, if the manager dissatisfied with the status quo, he or she will need management innovation. Dissatisfaction to the status quo may come from the performance of management that did not achieve the desired goal of managers and fail for commercial competence. (2) Turn specific problems into specific conflicts. This step turns the factual innovation problems into one or several specific conflicts of an enterprise, and adds the conflicts into in general Conflict Matrix. (3) Turn specific conflict into conceptual conflict. The process required to refer the Management Parameters as seen in Table 2 into the Conflict Matrix. (4) Seek the conceptual solution. The conceptual solution can be solved based on the 40 Inventive Principles. The conceptual solution can solve the conceptual conflict based on the existing knowledge and experience of enterprise manager. The number of solution should be more than one in order to give options for the manager to choose according to the practical situation. Too much general solutions should be avoided. (5) Determine the specific solution. Conceptual solution offers a wide range of most likely solution. For a specific business, it is not easy to determine the specific solution from the conceptual solution. Feasible conceptual solutions should be obtained by gradually narrowing the scope of available conceptual solutions. (6) Determine the appropriate solution. Specific conceptual solution is only for a specific conceptual conflict, without considering the actual situation of enterprises. The Enterprise Environmental Parameters can be applied to explain the effect of actual situations. (7) Determine the ideal solution. In TRIZ, the ideal solution means that one can achieve the least investment and stack effects. In reality, such ideal solution does not exist. However, the near-ideal solution can be pursued 
instead. The index of ideality can be applied to quantify the level that close to the ideal. (8) Implement. As soon as the ideal solution was determined, it is necessary to implement the solution to deal with the factual problem. One thing important is to measure the ideality of the ideal solutions as feedback in order to determine if the loop should be continue or not.

\section{Summary}

This paper gave an overview of the conflict-solving for the management and technical innovation based on TRIZ theory. The 40 Inventive Principles that commonly applied in technical area is compatible to the management innovation even though several modifications must be made in accord with the enterprise practice. 39 Technical Parameters can be used to identify the specific problem in the Conflict Matrix, however, still require to be modified to suit for the management innovation. It is necessary to reduce the number of Management Parameters to get an appropriate solution for the Conflict Matrix. In order to eliminate insignificant invective principles and parameters for the conflict -solving, the practical Enterprise Environmental Parameters must be taken into consideration. The ideality of the solution should also be measured/evaluated in the process.

\section{Acknowledgement}

This research was financially supported by the Hebei Natural Science Foundation Project: Management Innovation based on TRIZ theory (grant NO. G2013202184).

\section{References}

[1] I. M. Ilevbare, D. Probert, R. Phaal, A review of TRIZ and its benefit and challenges in practice, Technovation, (2013) 30-37.

[2] D. L. Mann. Inventive (business) principles with examples [J]. The TRIZ Journal, 1999, 9. Information on http://www. triz-journal.com.

[3] B. Zlotin, A. Zusman. TRIZ beyond technology: the theory and practice of applying TRIZ to non-technical areas. The TRIZ Journal, 2001, 1. Information on http://www. triz-journal.com.

[4] V. R.Fey , E. I.Rivin, The Science of Innovation: A management overview of the TRIZ methodology. The TRIZ Group, Southfield, Michigan, USA. 1997.

[5] J. Hipple. The use of TRIZ separation principles to resolve the contradictions of innovation practices in organizations, The TRIZ Journal, 2004, Information on http://www.innovation-triz.com.

[6] G.Martin, H. Lessing. Profiling technological competencies of companies: a case study based on the theory of inventive problem solving. Creativity and Innovation Management Journal, (2004)231-238.

[7] R. Vries, V. Souchkov, J. Mannak. Remote Team Problem Solving With TRIZ [J]. The TRIZ Journal, 2008, 7. Information on http://www. triz-journal.com.

[8] G. Altshuller, The innovation algorithm: TRIZ, systematic innovation, and technical creativity. Technical Innovation Centre, Originally published in Russian 1969 and 1973, Worcester, Massachusetts, 1999.

[9] K. Rantanen, E. Domb, Simplified TRIZ — new problem solving applications for engineers and manufacturing professionals. Auerbach Publications, New York, 2008.

[10]B. Ruchti. TRIZ-based innovation principles and a process for problem solving in business and management. Proceedings of the European TRIZ Association, (2001) 151-158.

[11] D. Stephen .The Inventive principles of TRIZ applied to finance. The TRIZ Journal, 2004, 10. Information on http://www.triz-journal.com. 
[12] D. L. Mann, The next common sense: philosophy-level integration of TRIZ into an integrated business and management innovation process, in the ETRIA TRIZ Future Conference, Italy, 2004.

[13] O. Farias. The logistic innovation on approach and the theory of problem solving. The TRIZ Journal, 2006, 1. Information on http://www.triz-journal.com.

[14] R. Gennady, Inventive principles in marketing, sales and advertising. The TRIZ Journal, 2005, 4. Information on http:// www. triz -journal.com.

[15] J. Zhang, K-H. Chai, K-C. Tan, Inventive principles with applications in service operations management. The TRIZ Journal, 2003, 12. Information on http://www.triz-journal.com.

[16] P-K. Lam, K-S. Chin, Identifying and prioritizing critical success factors for conflict management in collaborative new product development. Industrial Marketing Management, (2005) 761-772. 